\title{
Textos y contextos de antiguas versificaciones rurales en Castilla y León
}

\author{
Texts and contexts of ancient rural versifications in Castilla y León
}

María Pilar Panero García

Profesora Asociada, Departamento de Prehistoria, Arqueología, Antropología Social y CC. y TT. Historiográficas, Universidad de Valladolid (España)

mariapilar.panero@uva.es

\author{
IMPROVISACIÓN POÉTICA Y PERFORMANCE. ASPECTOS ANTROPOLÓGICOS, LITERARIOS Y \\ MUSICALES. \\ MONOGRÁFICO COORDINADO POR MARÍA PILAR PANERO GARCÍA (Universidad de Valladolid)
}

Patrocinado por la Cátedra de Estudios sobre la Tradición (Universidad de Valladolid)

\section{RESUMEN}

Este artículo se centra en varios contextos rituales de Castilla y León en los que los textos poéticos son centrales en la celebración. Estos eran elaborados ex profeso para cada ocasión por versificadores locales; sin embargo, muchas han desaparecido, otras se han fijado a través de los cancioneros o de copias manuscritas y se repiten año tras año como forma fija y algunas se mantienen, aunque amenazadas por cambios de calado en los ritos y la atonía demográfica. Los brindis y agasajos, los ramos como cánticos y poesías de bienvenida, las relaciones de quintos en ritos de paso a la edad adulta nos servirán de ejemplos.

\section{ABSTRACT}

This article will focus on several ritual contexts in Castile and León in which poetic texts are central to the celebration. These were elaborated expressly for each occasion by local versifiers; however, many have disappeared, others have been fixed through songbooks or manuscript copies and are repeated year after year as a fixed form, and some remain, although threatened by profound changes in the rites and demographic atony. The toasts and feasts, the bouquets as songs and poems of welcome, the relations of quintos in rites of passage to adulthood will serve as examples.

"Hilo de Ariadna es el verso. / Trama o trampa, lo perfecto" (Gabriel Celaya)

\section{Improvisación, oralidad y versificadores populares}

La Antropología desde su implantación ha puesto el foco en las relaciones entre lengua y cultura. Ha contribuido al conocimiento de la oralidad en las sociedades ágrafas o en aquellas que tienen un uso restringido de la escritura. Situaciones de oralidad primaria se han dado, y se dan con desigual vigor en nuestras sociedades occidentales. Así, hechos como los de realizar una invitación, mostrar gratitud, impartir justicia o contar historias perviven oralmente en sociedades que han asimilado la escritura en diversos contextos: "Las culturas orales tienden a utilizar los conceptos en marcos de referencia situacionales y operacionales abstractos en el sentido de que se mantienen cerca del mundo humano vital" (Ong 1982: 55). El propio Ong (1982: 114-116) habla de la persistencia de la oralidad en el "arte" de la retórica que llega hasta hoy haciendo pasar por orales discursos escritos en un remedo de improvisación que aspira a "volver" a un origen prístino de la palabra.

El repentismo se ha dado en diversos lugares y contextos como prueba de ingenio en las veladas literarias y poéticas en combates en público, antes mencionadas, o en eventos privados. Sin embargo, no sería exagerado afirmar que en muchas composiciones y verbalizaciones públicas de fiestas y regocijas subyace también un repentismo que se pone de manifiesto en performances públicas en las que prima la 
memorización de versos.

Hay dos configuraciones relacionadas con los transmisores-autores que propician cambios en las estructuras literarias tradicionales que las conservan y al mismo tiempo las hacen evolucionar. Una se debe a la figura del marginal, definido por Joaquín Díaz (1983) como el "personaje que vive en una comunidad pero no está totalmente integrado a ella; no pertenece a la base del pueblo y, de vez en vez, introduce elementos de una cultura distinta en el caudal de conocimientos colectivos". Estos marginales pueden ser el ciego que canta y vende romances, el alcalde que prohíbe o consiente las costumbres, el cura que añade canciones al repertorio en los ritos, el músico que allega los temas de la ciudad y los incorpora en el baile tradicional, etc.

La otra configuración, definida por José Luis Alonso Ponga (1979: 168-170), es la de los versificadores populares como otros personajes responsables de este modelo de cultura tradicional que se ha transmitido por tradición oral. Son personas de la localidad que conocen perfectamente sus códigos culturales, el sentido profundo de las tradiciones, y son capaces de plasmar con la mayor realidad las aspiraciones de la comunidad. Casi siempre estos versificadores habían tenido contacto con la segunda cultura, la hegemónica, bien por haber estado en el seminario, o por haberse preparado en las preceptorías donde se formaban los niños antes de ir a estudiar a otros lugares. En este caso son personas de mente espabilada, con una cultura especial dentro de la comunidad y, por supuesto, con una memoria privilegiada. Con frecuencia, su cultura procede de sermones, discursos de personas que han llegado de forma excepcional al lugar y no es raro el hecho de que no sepan ni leer ni escribir, lo cual en el contexto en el que deben desarrollar su labor no es una rémora. Por eso entremezclan palabras populares de uso cotidiano con otras cultas que ellos no comprenden, y probablemente tampoco los que las escuchan, pero que a los ojos del público son profundamente sonoras y portadoras de mensajes. Las obras literarias dejan constancia de la vida y don Quijote, personaje que nos desvela lo más insondable de los valores que sustentan nuestra cultura, se interesa por Crisóstomo, pastor y autor de versos bien hechos que "todos decían que eran por el cabo" (Cervantes 1605: 176-177).

Los versificadores controlan los códigos de la composición, de manera que el ingenio consiste, entre otras cosas, en dominar el vocabulario. Este debe ser siempre cercano al auditorio que debe celebrar el ingenio del vate más allá de juzgar la factura métrica de los versos y las rimas. Declamar en público no es un pugilato entre dos personas, aunque también hay duelos poéticos entre vates, sino entre todos los asistentes a la reunión. Estos deben ser ganados con cuentos, chistes, acertijos, metros bien compuestos y todos los medios que faciliten versos curiosos y agudos.

El compositor popular utiliza todos los medios que tiene a su alcance, los conocimientos adquiridos en los libros y fuera de ellos. Son personas de memoria prodigiosa y gran habilidad para trenzar versos y rimar ideas. Son biculturales. Están inculturados en las nomas de la cultura popular de la localidad, pero también en la hegemónica, pues participan de las dos y, por lo tanto, son capaces de utilizar los registros de ambas para sus intereses. Son personas respetadas intelectualmente en la localidad y en la comarca, a ellos se encargan los versos para las composiciones de las puestas en escena festiva de los momentos más importantes en el desarrollo de las identidades locales, comarcales y también individuales cuando se trata de ritos de paso. El versificador considera la música que con frecuencia le obligaba a utilizar un tipo de estrofa e incluso conservar algunas palabras de la estrofa maestra. En el año 1961 se cantó un ramo de bienvenida a un nuevo sacerdote en el que el compositor introdujo un estribillo, probablemente porque estos ramos lo exigían. Adecuó el estribillo al de la conocida "Jota de Boñar", como era habitual en muchas de estas composiciones (Alonso 1979: 169) por lo que no le quedó más remedio que mantener en la nueva composición la palabra del final de cada verso de aquella composición, como sucede en muchas canciones.

\section{Contextos performativos en Castilla y León}

Los contextos rituales en los que se recita poesía en Castilla y León son variados. Muchos han desaparecido o han cambiado tanto las circunstancias en las que se realizaban que son diferentes. Estos cambios se deben generalmente a recuperaciones o transformaciones profundas motivadas, entre otras razones, por la atonía demográfica de unos pueblos que se han vaciado. Por supuesto, estamos hablando de contextos en los que la asistencia del público en un contexto festivo, con mayor o menor afluencia, conforman todavía hoy la razón de ser del fenómeno de recitar versos. Somos conscientes de que no tratamos otros que sin duda son reveladores de la organización social en el medio rural como los 
otros ramos como el de Navidad (Alonso 1986). También obviamos composiciones poéticas que se dan en otros ritos del carnaval tradicional, que son parte de algunas mascaradas como Los Carochos de Riofrío de Aliste (Zamora), donde la acción es mayor que la palabra, pero esta es fundamental (Panero 2020: 49-56).

\subsection{Brindis y agasajos}

El brindis tiene el valor de ser una muestra de confianza hacia la persona a quien va dirigido. Es un valor que se ha mantenido desde su lejano origen, atestiguado ya en Grecia en el marco de la Guerra del Peloponeso:

"ordenaron silencio a voz de trompeta e hicieron sus votos y plegarias a los dioses, según costumbre, no cada nave aparte sino todas a la vez, por su trompeta o pregonero. Después bebieron en copas de oro y plata, así los capitanes como los soldados y marineros. Los mismos votos y plegarias hacían los que quedaban en tierra por toda la armada en general, y en particular por sus parientes y amigos" (Tucídides, Historia de la Guerra de Peloponeso: 558).

Lo que ahora son poesías de buenos deseos principalmente en un ambiente festivo alrededor del vino, formaban parte del antiguo symposion (banquete). Los brindis actuales se han organizado ya en colecciones (Sanz 1997: 27-32) que ahora son simples series de buenos deseos y acertijos. Estos se han encadenado entre sí y han pasado a la cultura hegemónica, aunque en un tiempo determinado fueron composiciones espontáneas. El modelo, que se ha mantenido tras una selección "natural" en la creación de la literatura de tradición oral, surge en contextos lúdicos. Los más logrados son ampliamente celebrados y finalmente trascienden al propio autor, que repetidos entre el pueblo acaban poniéndose por escrito y se difunden en cuadernillos primero manuscritos y después en colecciones (Sanz 1997). Muchos funcionan como tonadas que se interpretan fuera del contexto en el que nacieron (Manzano 2011: 657-663).

Los brindis son poesías cortas que uno de los comensales dedica a otro u otros invitados para celebrar su asistencia y, de paso, exaltar alguna de las cualidades o circunstancias que adornan al agasajado con intención de agradarlo. Eran habituales hasta los años sesenta en el mundo rural, declamándose habitualmente en las mesas de los clérigos y, con frecuencia, en las mesas de los pudientes que tenían invitados de categoría. Los clérigos estaban bien entrenados, porque también habían practicado este arte en el seminario como un arma de ingenio preparándose para predicar, según el mandato paulino: "Predica la palabra; insiste a tiempo y fuera de tiempo; redarguye, reprende, exhorta con mucha paciencia e instrucción" (2 Tim 4).

El ingenio les permitía acercarse a los feligreses en contextos totalmente lúdicos, pero de gran efectividad en la predicación no reglada. La tradición hoy perdida se recordaba aún en los años ochenta del siglo pasado, de hecho, así la recogió José Luis Alonso Ponga (1) en Aliste. Allí don Luis Rodríguez, párroco de Riofrío de Aliste y de Bercianos, pero natural de Sesnández de Tábara, en una entrevista en agosto del año 1983, le contó las celebraciones de las fiestas patronales de los pueblos de Aliste y Tierra de Tábara. En ellas se juntaban al menos tres sacerdotes, pues al ser misa de asistencia participaban siempre dos de los pueblos cercanos, aunque la fiesta también servía para invitar a otros sacerdotes a la comida especial. En estas mesas de fiesta había competiciones de versos improvisados que comenzaban con composiciones elegantes dedicadas al pueblo, a los vecinos y terminaban con ciertos piques entre los clérigos por ver quien componía mejor. En ocasiones, a estas contiendas poéticas acudía una apreciable cantidad de personas invitadas por el anfitrión a tomar el café después de la comida. Participaba un público expectante que transmitía lo que habían vivido dentro del convite y no faltaba algún asistente de memoria prodigiosa que retenía estrofas enteras y que le servían para sus nuevas composiciones. La misma tradición la recogía en la Vega del Esla y en los pueblos de la Tierra de Campos de Valladolid y Zamora, en estos últimos casos las noticias provienen de algunas "amas de cura" que la habían conocido en el primer tercio del siglo pasado.

En Serra San Bruno (Calabria) el profesor Alonso Ponga no solo la conoció, sino que fue y protagonista en un brindis cuando, la primera vez que estuvo, un sacerdote, con el vino servido en las copas de los comensales, le dedicó una quintilla saludando su origen, España, alabando su maestría en la conferencia que había dado y agradeciendo en nombre del pueblo su presencia en las jornadas culturales. Ante la consulta de si un brindis versificado era una costumbre calabresa, la respuesta fue que no tanto de Calabria como de los seminarios. Cuando este sacerdote estudiaba, en los años cincuenta, en las fiestas especiales se hacía una especie de disputa poética entre los seminaristas para ver quién era mejor 
improvisador.

La tradición recogida en Castilla y León, y muy extendida, tenía en común el origen clerical. Estas pruebas formaban parte de la formación en retórica y agudeza de ingenio que se exigía a los que se estaban formando para ser sacerdotes, donde el dominio del púlpito es una de las actividades más necesarias. Estos son testimonios de una tradición que tuvo gran vigencia en siglos anteriores. EI P. Isla, cuando cuenta el primer sermón de fray Gerundio de Campazas en su pueblo, además de extenderse refiriendo la oratoria de predicador, nos narra la opípara comida ofrecida por sus padres y los sucesos en la mesa. Allí, diversos religiosos que lo acompañan se explayan demostrando su agudeza improvisando versos que animan el convite. En el caso del P. Isla parece que los vates no están obligados a utilizar un metro concreto, ya que recitan en "disparatadas décimas", quintillas, una octava rima y una "disparatadísima chorrera de desatinos" en un ambiente de comensalidad en el "que atropellaban unos a otros los brindis y las coplas" (Isla 1995: 646-665) al grito de "Bomba". Si bien el que más utilizan los "grandes copleadores" en esta jocosa pugna repentista es la décima espinela, el metro más aceptado para la improvisación (Díaz Pimienta 2008 y 2013, Trapero 2020).

Probablemente la misma cuarteta que recoge el P. Isla, y que en su tiempo funcionaba como una prueba de ingenio y chacota en los seminarios de la Compañía, había nacido en un contexto similar años antes. Esta composición, como otras de esta obra, como no podía ser de otra manera en su género, mostraba el ingenio del autor a la par que se reía sibilinamente del sermón fraygerundesco e ininteligible con que les había honrado el predicador: "Vítor el padre Crispín, / De los cultos culto sol, / Que habló español en latín, / Y latín en español" (Isla 1995: 571).

Todo este bagaje pasa al pueblo y permanece en él. Entre los brindis que recogemos ahora en trabajo de campo y que el informante da como propio y distintivo de su localidad, hallamos composiciones populares que se rastrean desde el siglo XVII. Estos están mezclados con otros originales a los que se puede atribuir una autoría local que nacen en contextos que se ajustan a la dinámica del repentismo. La pervivencia se puede comprender teniendo en cuenta la mayor lentitud que hubo en el medio rural para aceptar las nuevas modas y desprenderse de las antiguas.

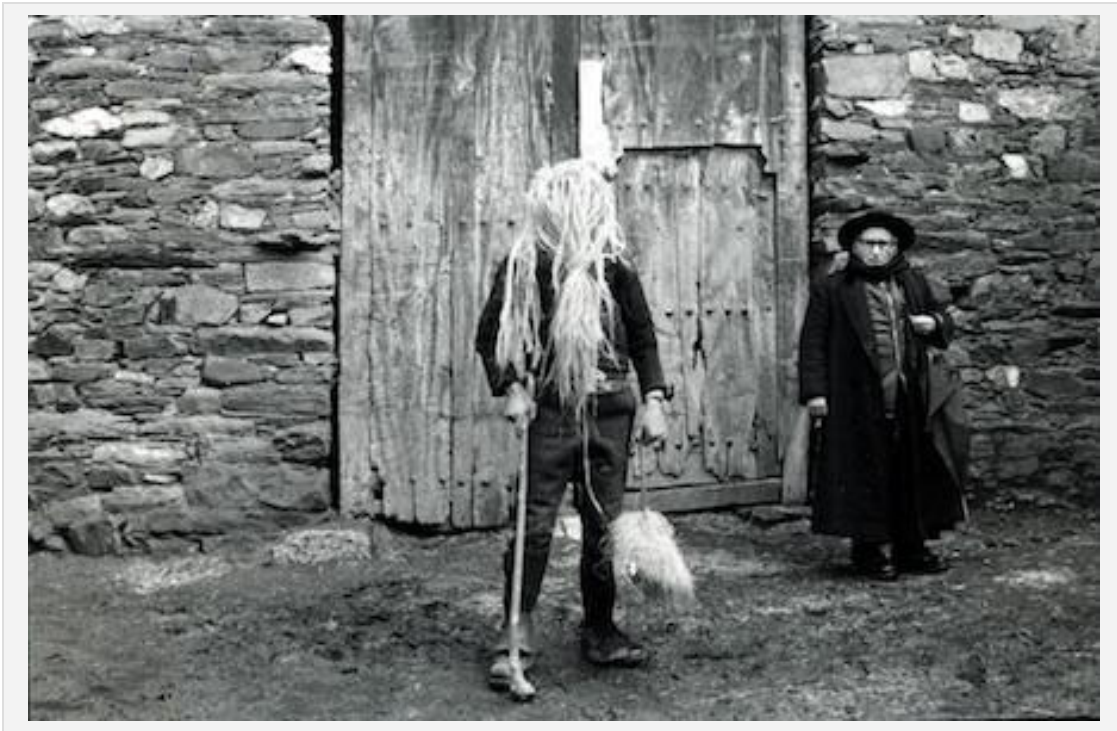

Don Luis Rodríguez con El del Lino, personaje de Los Carochos, en Riofrío de Aliste un 1 de enero en los años 70 . Todavía hoy, un sacerdote real sigue participando en la mascarada bautizando al hijo de la Madama. Hubo hasta los años de la emigración, que coincidieron con el Concilio Vaticano II, una clase de sacerdotes que comprendieron los ritos rurales y participaron ellos. Fotografía: Manuela Folgado (archivo familiar).

Hoy han desaparecido prácticamente los cantos de boda que se interpretaban la víspera, en la boda y en la tornaboda conservándose en los cancioneros (Manzano 2011: 600). Sin embargo, la improvisación como condimento hilarante del comensalismo en el mundo rural residualmente ha quedado fijado en los versos de los invitados a las bodas (2). En las bodas tradicionales hasta la despoblación rural era costumbre ofrecer a los novios los regalos de boda de forma pública. Cada asistente había entregado ya un presente, pero en los postres se lanzaba primero el padrino y después algunos invitados más rumbosos para entregar a los novios algún obsequio extra. Esto solía hacerse en verso, bien improvisado 
o bien compuesto antes, pero que siempre sonaba como nuevo porque el recitador lo exponía como original y propio en el momento de ofrecer sin que nadie sospechase ni el metro ni el motivo. Seguían la estructura de los cantos populares epitalámicos en los que se relatan los diferentes momentos del ritual popular y se expiden parabienes. Una vez más se ponía en evidencia el ingenio del vate que parte de algunas formas fijas: "Hoy te ofrece el tu padrino, / estos dos duros de plata / Dios te de mucha fortuna / en tu vida de casada".

\subsection{Poesías y cánticos de bienvenida: los ramos}

En la actual provincia de León y zonas limítrofes de influencia (Zamora, Cantabria, Asturias, Valladolid y Palencia) florecieron unas composiciones poéticas que se cantan denominadas ramos. El ramo, como el pendón, es un elemento cultural que pervive en su forma material en todas las comarcas leonesas convirtiéndose, especialmente el de Navidad, como un elemento identitario leonés resemantizado especialmente en ámbitos urbanos. Sin embargo, en lo que respecta a su parte inmaterial, se mantiene en muy pocos pueblos y de forma esporádica y anecdótica.

El ramo es un soporte material variado según las zonas (ramo verde o soporte de madera del que se cuelgan diversas ofrendas como lazos, frutas, rosquillas, velas, colonias, etc.), tiene una parte literaria compuesta por textos en verso musicalizados y forma parte de un ceremonial religioso o profano en el que participan los jóvenes, antes mozos y mozas. Los que perviven con más arraigo son los ramos de Navidad (Alonso 1986: 39 y ss., Valderas 2009) en su parte material y los patronales o votivos (Puerto 2010: 28-31) en su parte material y vinculados a romerías. Sin embargo, en el pasado fueron una composición habitual en ritos de cambio de estado como la boda, cantar la primera misa, entrar como sacerdote en una nueva parroquia.

El ramo como poema, sea cual sea su finalidad, tiene tres partes. Una primera con pocas estrofas en la que se pide licencia al sacerdote para acceder al templo o a una persona de autoridad para cantar, si es uno de boda. Cuando se concede se canta la parte central del poema con el ramo en alto y finalmente se cantan unas estrofas que sirven de despedida y en la que se piden las bendiciones.

Era costumbre en el mundo rural hacer discursos de bienvenida a las personas de mayor categoría social, fuesen estas políticas o religiosas. En ambos casos, se consideraba un honor que se relacionasen con el pueblo. Estas manifestaciones tenían lugar generalmente cuando cantaba misa un sacerdote oriundo o cuando un sacerdote foráneo hacía su nueva entrada como tal en un lugar. También se entonaban cánticos para situaciones excepcionales o esporádicas como la visita de un obispo, un responsable político o, con frecuencia, un noble o potentado el señor que dominaba a los campesinos. En estos casos, además de adornar el pueblo o al menos la calle por donde debía de pasar y la puerta de la iglesia, alguien, una persona de autoridad o en su defecto un niño o niña de la escuela, recitaba las estrofas de bienvenida. En su composición se seguían unas normas que habían llegado al pueblo en alguna publicación o por vía de los sacerdotes. Variaba, claro está, el nombre del homenajeado y las virtudes que se le atribuían hiperbólicamente. La composición puesto que no era habitual se sacaba de otras anteriores variando lo singular, o adaptando las mismas a estas circunstancias.

Fueron importantes como canciones de bienvenida los ramos de cantamisas. Cuando un hijo del pueblo volvía para celebrar la primera misa entre sus paisanos, era recibido por estos en un rito de paso, de reincardinación en el lugar de donde había salido varios años antes. Si el nuevo sacerdote pertenecía a una orden religiosa significaba que había estado separado entre ocho y doce años del pueblo, dependiendo de la orden en la que había ingresado, por lo que no había regresado desde que se marchó siendo un niño. Mientras que el resto de sus coetáneos habían evolucionado según la lógica de las ordenanzas concejiles siguiendo los ritos de paso del grupo, él regresaba sin haber superado las transiciones entre la juventud y la edad adulta siendo un extraño entre los suyos. Por ello se requería un rito de inclusión dentro del horizonte cultural y de la estructura de los grupos de edad, pues al regresar soltero y célibe era una figura diferente. Era un hombre consagrado a Dios compañero de sus compañeros y dentro de pueblo referenciado por la quinta, año de nacimiento, pero con otra categoría. 


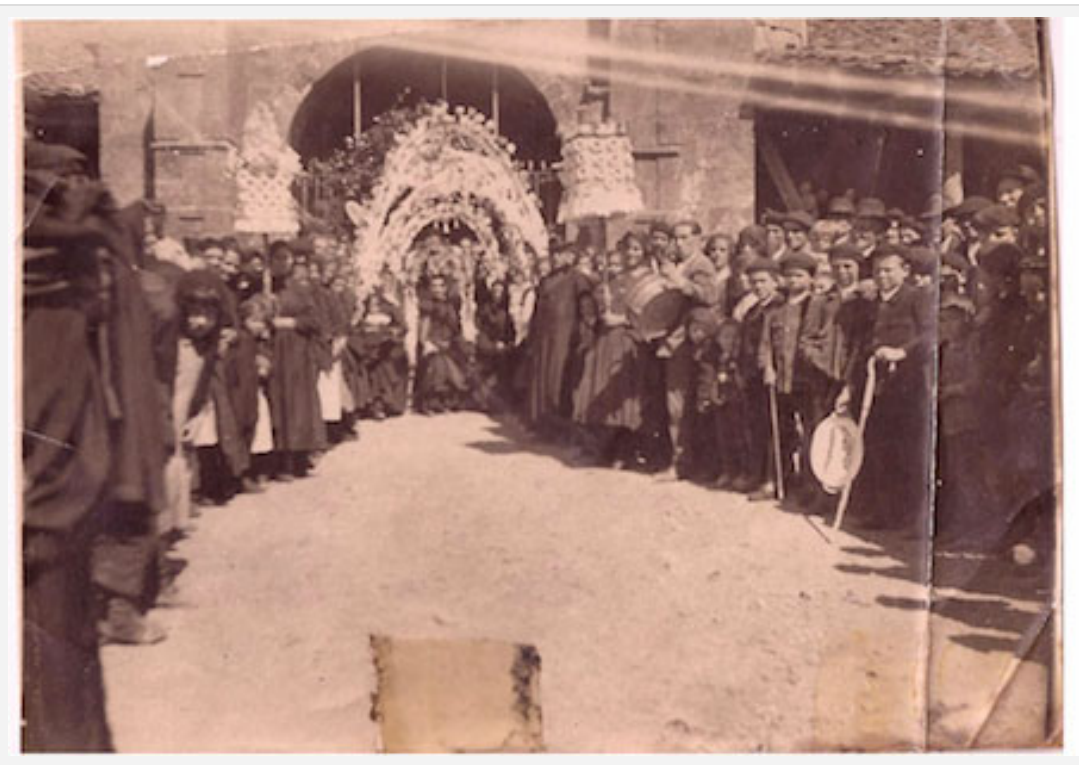

Ramo de cantamisas en Prioro hacia los años 30 del siglo XX. Fotografía: Asociación Cultural Tenada (León).

El tránsito a la adultez plena del sacerdote se hacía a través de un ritual complejo que no vamos a detallar, dentro del cual la parte más importante estaba en la "verbalización pública" del estatus nuevo del vecino retornado. Los quintos y quintas tenían sus papeles determinados, pero el de las quintas era el de cantar el ramo y ofrecérselo al sacerdote. La composición poética se encargaba a uno de los versificadores reconocidos en el pueblo o en los alrededores. El modus operandi de este vate era relativamente simple: las mozas se acercaban a encargar los versos, el versificador pedía los datos precisos (nombre del homenajeado, nombre de los padres, abuelos si los tenía, y hermanos, año de la quinta, orden religiosa a la que pertenecía y poco más). El resto lo componía siguiendo el esquema convenido recalcando: la generosidad de los padres que habían entregado un hijo a la Iglesia, el honor que representaba para el pueblo el tener un intermediario ante el Altísimo, la entusiasmada recepción que le hacía el pueblo, la alegría por su recuperación para la comunidad y una petición de que no olvidase a sus compatriotas tras su marcha. Abundan en los ramos la anécdota puesta en verso, la biografía y hasta la autobiografía del versificador, que exponía a la consideración y benevolente absolución del público a través de los cantores y cantoras que participaban en el mismo.

Hubo otros ramos relacionados con personas concretas que se hallaban en situaciones especiales. Estos abundan y se hacen especialmente importantes durante la guerra y en los meses inmediatos a su fin cantados como acción de gracias. Sucedió a raíz de la guerra civil y del resultado más o menos aceptable en el que se involucraron los mozos del pueblo, tanto los que murieron, como los que quedaron inválidos y los que desaparecieron. Los pueblos se hicieron un clamor de ramos cantados en acción de gracias a la devoción particular de cada una de las localidades, de manera que las devociones hagiográficas, pero, sobre todo, cristocéntricas y las marianas, incrementaron las oraciones colectivas a través de las romerías. Estas fueron el vehículo para ofrecer una acción de gracias con la que expresar la protección especial que los vecinos habían experimentado.

Este fenómeno fue aprovechado por el nacionalcatolicismo para recristianizar el mundo rural con los sermones y composiciones poéticas de curas trasnochados. En el urbano, además de los sermones, se aprovecharon los cancioneros para ensalzar la vida campesina como ontológicamente mejor pues en muchos casos "se conserva, con admirable integridad, la idea religiosa y con ella las costumbres cristianas de encantador idealismo" (Domínguez Berrueta 1941: 131). En definitiva, se aprovecha la religión oficial obligatoria para todos los españoles como en este ramo que recoge Mariano Domínguez Berrueta (1941: 230-231) procedente de Matanza (León):

"Buenos días, Virgen santa,

de España la salvación,

estas chicas de Matanza

suplican Tu bendición.

¡Virgen María la Blanca, 
escucha nuestra canción,

que estas mozas de Matanza

te cantan con devoción.

Y es para darte las gracias

por tu grande protección,

pues libraste a nuestra España

de extraña persecución".

\subsection{Composiciones carnavalescas de performance global}

Las performances en las que aparecen las composiciones versificadas son aquellas en las que tradicionalmente los mozos y mozas, ahora sustituidos por la juventud, son los protagonistas. Entre ellas estarían las rondas, aunque las que han llegado a nosotros lo han hecho a través de los cancioneros. Son, por lo tanto, las recopilaciones de maestros sacerdotes (Olmeda 1902) o de laicos (Domínguez 1941), amantes de la música y las tradiciones que las han rescatado con el lastre del espíritu romántico y las han elevado a la categoría de emblemáticas. Desde los últimos años del siglo XX disponemos de cancioneros que siguen criterios exclusivamente etnomusicológicos que evitan una recopilación estática y acumulativa y, si bien no están imbuidos del nacionalismo español de los tiempos pretéritos, sus publicaciones son auspiciadas por instituciones locales, provinciales o regionales en consonancia con la división administrativa y política de la España democrática. Estos últimos son numerosísimos, aunque valgan como ejemplo en Castilla y León los del maestro Miguel Manzano (1982, 1988-1991, 2001, 2011).

Cuando la performance moceril se da en un contexto de rito de paso la puesta en escena varía ligeramente, pero remarca más los caracteres de identidad individual de cada protagonista y del grupo en relación con los otros grupos que han hecho la transición antes que ellos o que la harán en el futuro.

San Antón, por ser el patrono de los animales, ha sido especialmente venerado en la ruralía. En los lugares donde se celebraba con categoría de santo patrono o con votos e villa tenían lugar las famosas vueltas de san Antón descritas en el s. XIX por Basilio Sebastián de Castellanos en Madrid (1848) y en esta villa y otros lugares como Barcelona o Illescas el "correr gallos" (1847: 40). Estas celebraciones en las que se sacrifican gallos han sido estudiadas por Caro Baroja (2006: 77-94) como una de las celebraciones del ciclo de carnaval muy extendidas en diferentes regiones de la geografía española.

Es el periodo carnavalesco (diciembre, enero y febrero; véase Caro 1965: 155-160), debido al desahogo prefijado y aceptado por los sectores hegemónicos de las distintas comunidades, el tiempo en el que se ha consentido de forma generalizada hasta tiempos recientes la costumbre de "echar refranes" o "echar la relación", poemas satíricos realizados generalmente por los mozos o por los versificadores locales y siempre declamados por los primeros. Estos versos, que se dedicaban a las autoridades con el fin de limar asperezas y descargar las tensiones propias de la convivencia, eran parte de la fiesta de los quintos.

Estas poesías forman parte de un ritual complejo en el que se realizaban las carreras de gallos, aunque, hoy día, en los lugares en que se siguen realizando, el tótem primitivo, que encarna la "cabeza dominante" a la que hay que burlar durante el tiempo en que se permite la subversión, ha sido sustituido por cintas o por un animal ya muerto. Este rito ancestral, en el que los jóvenes mostraban su valía ante el resto de su comunidad, se ha ido adaptando a los tiempos, o bien porque prima la sensibilidad y el respeto a los animales o bien por las prohibiciones (그). La escasez de caballerías en los pueblos que poco a poco han sido suplantadas por la maquinaria, ha sido otro factor de la decadencia de esta costumbre.

En las provincias de León, Palencia, Valladolid, Salamanca y Zamora se conservan algunos ejemplos de lo que en estos rituales se denominaban "echar los refranes", recitar poesías muchas veces ante la imagen del santo o de la Virgen o ante la comunidad. Como en tantas otras ocasiones han llegado hasta nosotros algunas de las composiciones más celebradas por el público. Los mozos tenían que echar cada año un refrán nuevo. Dependiendo de los lugares, como no todos estaban dotados para el arte poético, se podía encargar su composición la persona más entendida, aunque los versos que se improvisaban eran añadidos a otros que se repetían con posibles variaciones todos los años. En Autilla del Pino (Palencia) se recitaban en san Antón algunos dedicados al Santo de carácter solemne con otros de carácter jocoso (ㄴ) : 
Al ser una celebración carnavalesca se buscaba el divertimiento de los asistentes, pero también una de las finalidades del ritual es la cohesión social. Cada uno de los protagonistas acudía "en secreto" a pedir al compositor unas coplas. El versificador o versificadores hacían las de todos, aunque las individualizaban de manera que parecía que eran los propios quintos los autores. La ventaja estaba en que, al controlar las de todos, podían ironizar sobre los protagonistas, toda la comunidad, siendo una manera de purgar las faltas o deslices, especialmente las femeninas y las de las autoridades, que atentaran contra la moral y orden públicos. El fundamento de estas composiciones es precisamente la catarsis colectiva que suponía hacer públicos los "secretos" que todos conocían extraoficialmente.

En Renedo de Esgueva (Valladolid) se celebró la carrera de gallos en carnaval por última vez en el año 1938 y las personas de más edad recuerdan que participaban varios mozos con varios roles: un capitán y varios soldados y un defensor de los gallos. Estos personajes recitaban romances, tiradas más o menos fijas, sobre las que se podían hacer variaciones referidas a la fiesta de ese año o chascarrillos referentes a la vida en el pueblo desde la celebración anterior. Los mozos establecían un diálogo en función de su papel de defensor y de capitán. Y se concluía ajusticiando a cada uno de los gallos:

"Ese gallo cantarín

que está detrás de la puerta

a mí no me deja dormir

y a mi novia la despierta.

Ese gallo cantarín

que come trigo y cebada

ha de venir a morir

a la punta de mi espada" (므).

En general, estos ritos desaparecieron poco a poco tras la guerra civil manteniéndose en muchos lugares hasta la emigración masiva a partir de la década de 1950. En la década de 1970 todavía se mantuvo en algunos lugares y en otros ha perdurado con transformaciones sustanciales o con simplificaciones.

En Sayago fueron generalizados los juegos de gallos en carnaval, manteniéndose en Carbellino de Sayago (Zamora) hasta el año 1990 (Sánchez Gómez 1991: 279). Luis Antonio Domingues Polanah (1996: 299 y 374), antropólogo portugués que en los años 1978 y 1979 hacía trabajo en Almeida de Sayago para escribir su tesis dirigida por Carmelo Lisón, presenció allí la carrera de gallos en carnaval.

En San Cebrián de Campos (Palencia) los quintos siguen recitando las cuartetas de san Antón a lomos de caballerías. Esta fiesta se ha fundido con otra antigua, que se denominaba Fiesta de quintos, en la que se celebran distintos actos como una cuestación en Nochevieja y se alargaba hasta el lunes siguiente al primer fin de semana de enero con el sacrificio del gallo, hoy perdida: "El lunes por la mañana los quintos dan otra vuelta al pueblo, pero esta vez acompañados por un gallo atado a una criba adornada con esquilas y cintas. El gallo borracho será sacrificado y servirá de cena a los quintos" (므). La fiesta de quintos y san Antón se celebran actualmente el segundo fin de semana.

En Valdecarros (Salamanca) donde se ha perdido la carrera de gallos y la de cintas que la sustituyó, la celebración era un complejo ritual de tres días, desde san Esteban hasta los Santos Inocentes, aunque el grupo de los mozos, como en muchos lugares, operaba en otros momentos como los días de Ánimas y de Todos los Santos (Rodríguez González 2002: 39). Se ha simplificado manteniendo solo algunos de los actos concentrados 28 de diciembre: "La horca", la corrobla (antes petición de aguinaldo cantando un repertorio más o menos fijado de coplas y rezando en las casas que ahora es la cena) y baile. En estos destaca "La horca", juicio satírico que representan los quintos a los que se han incorporado las quintas que representan los papeles de reo, su mujer, el juez y el verdugo. El primero que llega a la "horca" a lomos de un burro será ajusticiado después de contar todas sus fechorías, y ya de paso repasar las de sus quintos y vecinos del pueblo, en coplas. Estas se elaboran cada año por los propios quintos que recurren a personas con facilidad para componerlos, que pasan a la historia local del pueblo como el párroco Juan de la Cruz, homónimo del poeta del Carmelo que prestó ese servicio unos treinta años (Rodríguez González 2002: 45). El juicio concluye con un remate fijo: "Por sus muchas fechorías, I porque ha hecho mucho mal, / a este grandísimo endino / le vamos a ajusticiar". 


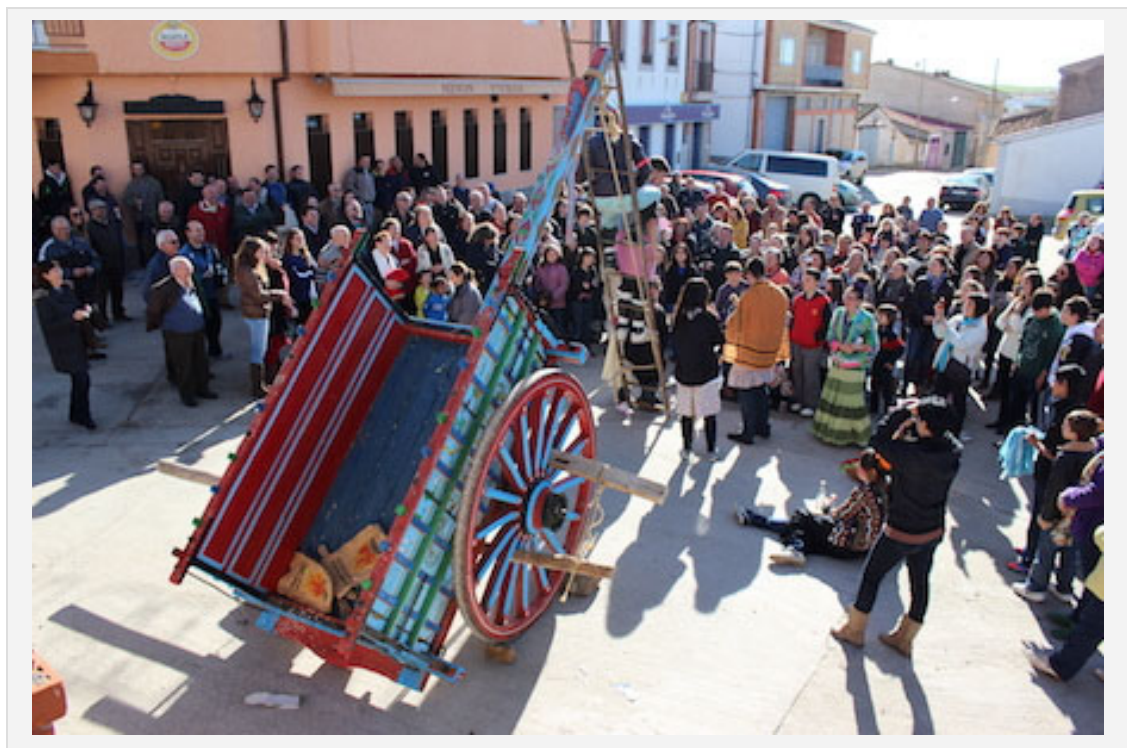

Los quintos de Valdecarros con "la horca" desde la que desarrollan su juicio satírico compuesto en coplas. Los cargos que le imputan al reo antes de ajusticiarlo son los chismes y anécdotas sucedidas en el pueblo el último año. Fotografía: Juan Francisco Blanco (Archivo IDES).

\section{Un ejemplo vivo de versificadores locales: los "relacioneros" de Guarrate}

Un ejemplo que perdura adaptándose a los tiempos es la fiesta Correr el gallo de Guarrate (Zamora), aunque algunos años no se ha celebrado por la falta de quintos (7). Incluso manteniendo muchos elementos primitivos que hacen que la fiesta sea percibida por propios y extraños como la de siempre hay cambios de calado: se ha adecuado a los discursos de igualdad de género (으); prima el respeto por los animales, pues los animales se han sacrificado previamente; la fecha de la celebración, incluyendo los preparativos, la pauta el calendario laboral actual; y los protagonistas del rito no lo son por tener la edad de cumplir el servicio militar, obligación obsoleta, pues son varones y mujeres que cumplen la mayoría de edad legal que, además, necesariamente no viven en Guarrate, sino que son hijos o nietos de emigrantes (Alonso 2012: 10 y 25). Si bien hay campesinos hoy día, estos se han transformado en su mayoría en perfiles empresariales. A esto se suma que la estructura social rural preemigración es minoritaria y convive con otros agentes sociales, especialmente retornados, trabajadores urbanos y población pendular, pudiendo haber otros como los neorrurales (Roseman 2013: 3). 


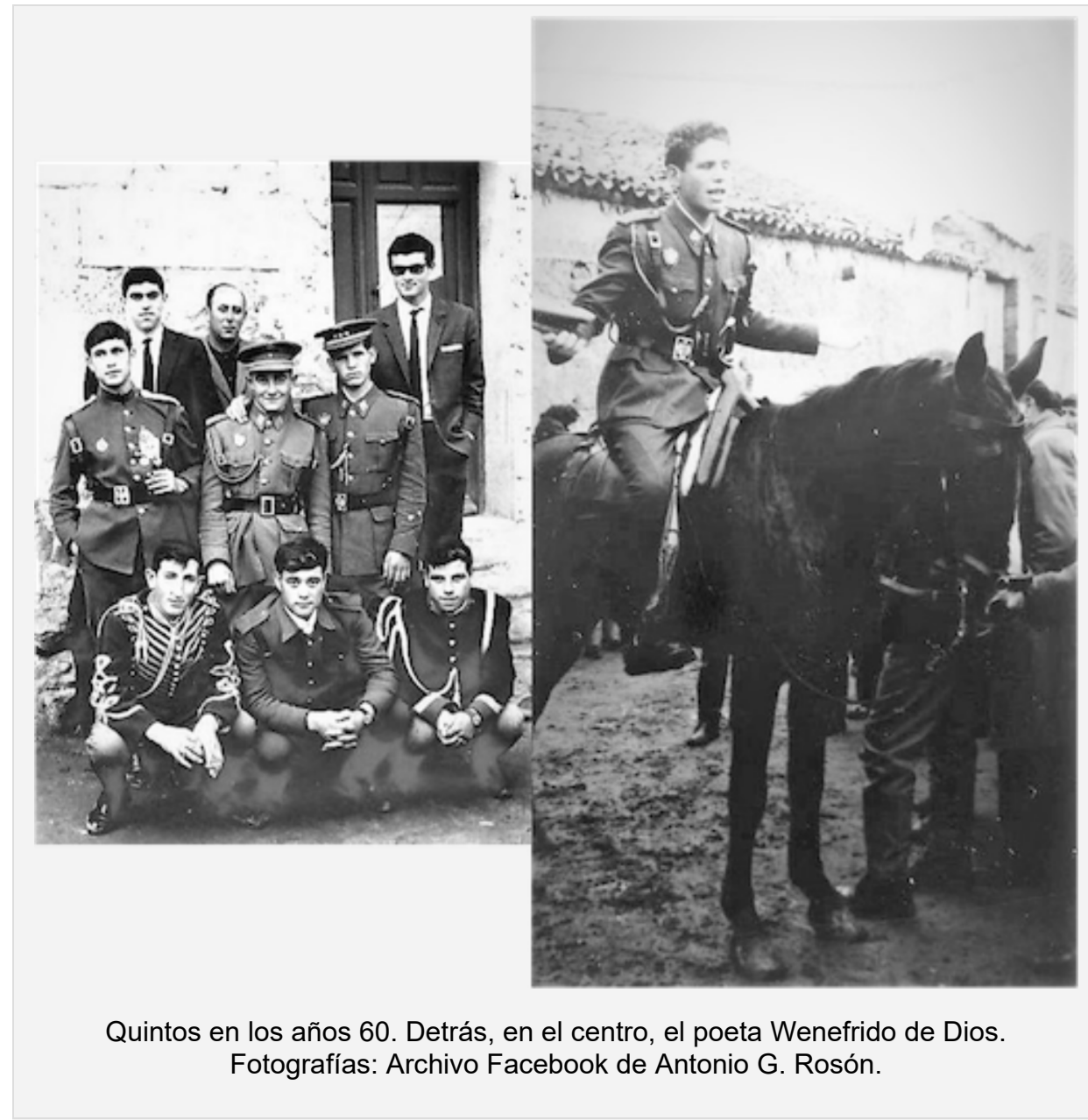

No vamos a hacer una descripción densa del rito de Guarrate, que podemos encontrarla en otros autores (Rodríguez 2006: 85-89, Alonso 2012: 12-19), o de otras de la zona como El Pego (Benito 2006: 6-9). Hay varios momentos en la fiesta que son sobresalientes: la misa, correr los gallos y las relaciones, las de los quintos y la del gracioso, y la cena pantagruélica. Las relaciones en décimas espinelas y quintillas con diferentes rimas, se hacen actualmente por poetas locales, como el periodista Luis Miguel de Dios (.9), también compositor en la vecina localidad de El Pego.

La relación se divide en tres partes de extensión variable según los casos. La primera es la parte noble y emotiva que tiene el preceptivo saludo y en la que se cantan las alabanzas del pueblo. En esta parte puede colarse alguna crítica sobre la realidad social y cultural de los pueblos, por ejemplo, relacionada con la despoblación. La segunda parte es el nudo, la relación propiamente dicha, en la que con un lenguaje mucho más llano se cuentan los defectos del quinto y su familia y entorno. La tercera y última es el cierre con la despedida y la condena del gallo. La relación comienza con décimas espinelas (abba / ac / cddc) en las que muchas veces siguen el esquema tesis (redondilla), puente (dos versos) y conclusión (redondilla) en un número variable que corresponde con la primera parte emotiva. Después se suceden quintillas (abaab / ababa / abab / aabab) en el nudo. El cierre puede ser con una décima espinela o con una quintilla según la relación. Ponemos un ejemplo reciente, dos décimas espinelas en la que una pertenece todavía a la parte emotiva, la han precedido siete, y la otra ya introduce la parte jocosa de forma bromista. El auditorio sabe que la relación no la ha compuesto su padre, sino otro miembro de la comunidad conocido por todos. El resto de la relación son en quintillas que aluden en primer lugar al padre y después a otros miembros de la familia incluida la quinta:

De Guarrate enamorada, lo defiendo con pasión, lo quiero con devoción como una joya sagrada. A su memoria entregada por cumplir hoy este rito,
Pensará la vecindad con el ánimo encogido:

Ana nos ha sorprendido, qué gran sensibilidad. Si les digo la verdad, esas frases no son mías. 
con un amor infinito, mando un saludo ferviente: ¡Larga vida a los presentes! ¡Un beso, pueblo bendito!
Es ajena la autoría.

Aunque a alguno no le cuadre, me las escribió mi padre, el rey de la simpatía.
10

Apenas oírlo hablar la alegría se le nota. Nunca para de cantar $y$ antes de desayunar se pone a bailar la jota.
11

En las juergas una fiera.

Lleva la farra en el alma.

Va de fiesta con cualquiera

y si escucha tocar palmas

se arranca por peteneras.
12

Con los que suele cazar ha reunido un elenco con una gracia sin par. Creo que van a actuar en un tablao flamenco.
Grupo con arte y salero. Cante jondo, canastero. Mi padre, de cantaor, Jaime y Álvaro, palmeros y Fernando, el bailaor.

\section{4}

Cuando caza la cuadrilla no acaba de rematar.

pero si hay que comparar es la que más bichos pilla a la hora de almorzar.

En este rito tenemos una muestra viva de lo que han sido hasta los años 50-70 del pasado siglo los versificadores locales. Para componer deben conocer al declamador, a su familia, la relación que estos tienen con la comunidad y los acontecimientos surgidos durante el año. El relato individual y colectivo entrelazado es propio de este tipo de composiciones que pertenecen a una tradición discursiva en la que el versificador y el recitador no son la misma persona, pero existe entre ellos una fuerte imbricación (Weber-Antón 2017: 34-35). Estos ingredientes, materia narrativa de la relación que cada cual expondrá en su turno, serán los "delitos" que cargarán al animal que expiará las "culpas" del joven en la incruenta carrera. Estas se purgan no solo con las autoridades, sino con todos aquellos con derecho hasta ese momento, de hacer injerencias en su educación como padres, abuelos, tíos y, por supuesto los vecinos.

El versificador tiene actualmente una dificultad añadida con respecto a los que tenían antiguamente este cometido, pues los que participan, no solo los corredores, sino también el público que asiste, no viven en el pueblo en muchos casos. Sin embargo, este tiene recursos para enterarse de la historia familiar y narrarla de forma satírica como corresponde al contexto festivo. La comunidad, aun estando en diáspora la mayor parte del año conoce la historia y las noticias locales y, lo que es más substancial, sus defectos y los de su familia que serán expuestos pues el quinto "se pone a parir", "aguanta el chaparrón", "dice cosas fuertes" provocando la risa. Incluso hay quien ve en esta catarsis familiar una terapia efectuada mediante una reescritura de las vidas y sus relaciones sociales que organizan la experiencia futura y la autoimagen (Benito 2006: 9-13).

En los últimos años los vecinos de Guarrate han hecho la transición de celebrar un rito comunitario, que tenía sentido exclusivamente para sus miembros, los de una comunidad de menos de 500 habitantes, hacia una espectacularización de la extinta vida campesina. Ahora el rito que funciona en la comunidad también se ofrece para el consumo de extraños que lo presencian o pueden tener acceso a través de Internet. En el año 1991 reflexionaban sobre esta cuestión varios entrevistados jóvenes (quintos y quintas de ese año y quintos que lo habían sido en la década de 1980) y mayores en un documental autoproducido por Antonio G. Rosón, descendiente de un emigrado, pero conocedor de la tradición (10 $)$.

Algunos de los participantes destacan que los medios de comunicación ponen el foco en el sacrificio del gallo, cuando lo realmente central en el ritual es la relación. Esto lo comunicaban en un año en el que todavía se sacrificó a los gallos en la carrera, la ley autonómica de protección animal de Castilla y León es del año 1997. Pero la presión de los grupos de activismo animalistas sobre toda manifestación cultural como una forma de opresión encubierta a los mismos y las prohibiciones del Gobierno Civil de la provincia habían logrado su cometido antes de la promulgación de la ley. En Villamor de los Escuderos en los años 1993 y 1994 los gallos no se sacrificaron públicamente, sino que se colocaron vivos en una cesta engalanada con cintas (Temprano 1995: 170-171). 
Los entrevistados no lo verbalizan, pero en sus comentarios hay cierto hastío ante la incomprensión de la fiesta que se expone al tamiz del movimiento animalista, que solicita la concesión de derechos a determinadas especies animales. Sí lo verbaliza uno de los dos quintos que hacen su relación en 1997 que afirma que se ha interpretado mal, que lo importante es la relación, la fiesta, porque es lo que une a todos, a jóvenes y a mayores, y que "el gallo tiene su importancia, pero es lo de menos" (Pellicer 1997). Para los guarrateños sus jóvenes se hacen adultos abandonando la vida que han tenido hasta ahora mediante la relación en la que dar muerte al gallo, ahora simbólica y antiguamente literal, era solo el cierre de la relación. De hecho, la ley cambió y se cumple. El nuevo contexto da al ritual un sentido ético y antropológico en consonancia con los valores que hoy se tienen proclives a la abolición de la crueldad hacia los animales, pero sin desmerecer su propia identidad.

Además, un hombre mayor, Paco "el Colorao", que de mozo dijo la relación, hace la siguiente reflexión de calado, y lo hace antes de que con la implosión de las redes sociales se difundan este tipo de ritos:

"Quizá lo que nos estás haciendo ahora [grabar un documental] perjudique al gallo. Los vídeos perjudican al gallo, las grabaciones perjudican al gallo. Porque antes [la relación] era algo que se oía y se olvidaba. Se recordaba de viva voz de padres a hijos, relaciones, cachondeos... Y ahora no ocurre" (Rosón 1991).

En estas palabras refrendadas por un quinto está la clave de algunas explicaciones acerca de la censura por parte de los relacioneros, nombre que denota praxis y oficio, pero que no es de uso común en Guarrate. A veces, aunque las ocasiones no han sido numerosas, las familias han aplicado correcciones o mutilado la relación de su quinto, o son los propios poetas los que se imponen la censura en el proceso de creación. Como sucede en otros lugares en los que los quintos exponen su vida (Weber-Antón 2017: 35), estos en última instancia tienen potestad para filtrar aquello que osan declamar en público. Coinciden en que antes, cuando solo se conservaban los versos en la memoria de los escuchantes, "se decían cosas más fuertes" (Rosón 1991). Se ha explicado la evolución de un estado de conciencia prelógico, propio de una mentalidad primitiva, a un pensamiento más racional como consecuencia de la asimilación de la escritura o de otras formas de fijar la oralidad en las sociedades occidentales. No estamos ante una división estricta entre oralidad y escritura, pero Paco ha dado con la clave: la escritura (dícese audiovisuales que fijan la palabra) modifica hondamente las sociedades y las conciencias de los individuos porque, como Goody (1977: 55) expone:

"cuando una expresión se pone por escrito puede ser inspeccionada con mucho mayor detalle, tanto en sus partes como en su conjunto, tanto hacia atrás como hacia adelante, tanto fuera de su contexto como en su lugar; en otras palabras, puede ser sometida a un tipo de escrutinio y de crítica bastante diferente del que es posible con una comunicación puramente verbal. El habla no está vinculada a la 'ocasión' por más tiempo, llega a ser atemporal, ni está atada a una persona; sobre el papel, llega a ser más abstracta, más despersonalizada".

Decir la relación y correr el gallo es un hito en la vida de los guarrateños que se fija desde el momento en que nacen. Es frecuente que tras un nacimiento o la celebración de una primera comunión los parabienes sean desear que pueda llegar a celebrar "el gallo". A pesar de esta flexibilidad del ritual, seguimos asistiendo a un rito de paso, el de la mayoría de edad en su comunidad o en la comunidad de sus antepasados, que sigue siendo una referencia identitaria para aquellos que habitan ciudades. Estos jóvenes, independientemente de su género, se hacen hombres y mujeres adultos en la comunidad que los ha visto nacer. Sin embargo, se han perdido algunos significados del rito antiguo como el de fecundidad asociado a la virilidad masculina (Caro 1965).

Otras significaciones como el de rebelión para reestablecer el orden social por medio de la palabra, si no se han perdido, al menos se han disuelto puesto que el foco se pone parcialmente en la comunidad concreta ampliando el arco a la actualidad global. La crítica social no se ejerce solo con los vecinos, sino que la relaciones versan sobre temas de actualidad. Un ejemplo es el gracioso, que en el rito tradicional declamaba su relación interrumpiendo a los quintos para que perdieran el hilo de la suya, mientras que actualmente tiene un papel independiente de las que recitan el ejército de los corredores sobre sus caballerías y en otro momento (Alonso 2012: 16). El gracioso, disfrazado de obispo, gobernante o famoso de crónica social (el conde Lecquio, Mick Jagger, un musulmán, etc.) se mofa de la actualidad nacional e internacional y de usos y costumbres generalizados con la única intención de hacer reír. Frente a la seriedad de los quintos sin impostura diciendo su relación, en la del gracioso prima la vis cómica, que se implementa con el disfraz y algunas improvisaciones al interactuar con el público. 


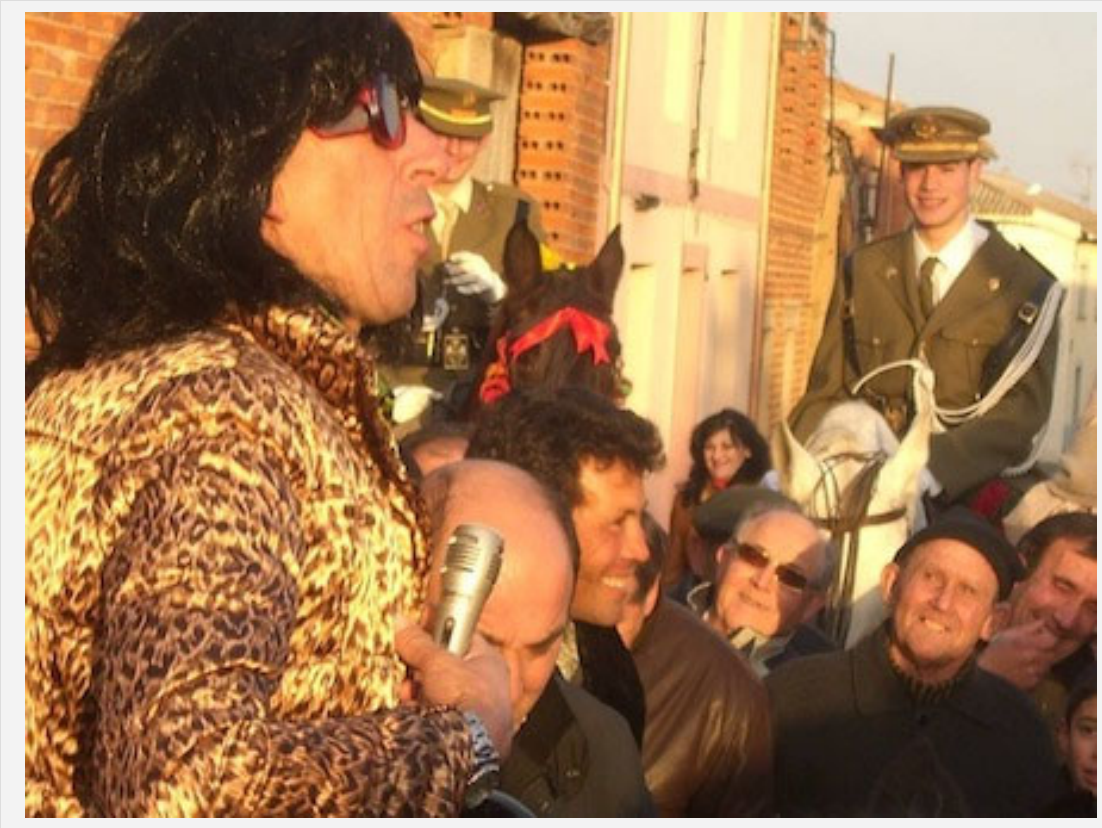

Ruperto Valdunciel caracterizado de Mick Jagger en 2007.

Fotografía: Antonio G. Rosón.

El versificador daba los versos al declamador con un margen de tiempo escaso en el que debía aprendérselos prácticamente de memoria para recitarlos ante el severo tribunal, que era todo el pueblo reunido en el acto, el juicio sumario al gallo. Si bien estaba permitido acudir con un "apuntador" de confianza, era deseable no recurrir al mismo y hacerlo sin fallos. Errar podía suponer pasar a la historia local con deshonor. En la performance actual se sigue demostrando el valor que tiene cada uno de los quintos a través de la poesía narrativa, pero la interlocución y dialógica entre protagonistas y textos enriquece aún más el valor de estas ingeniosas composiciones en las siempre, si la memoria falla, hay margen para improvisar. La palabra hecha relación dentro del rito contribuye a reforzar unos valores patrimoniales y étnicos inherentes a la tradición. Estos conforman el sentimiento de pertenencia a una familia nuclear y un lugar en el que mora una familia extensa. La debilidad poblacional, la desestructuración rural de los grupos de edad, así como la de los diferentes estadios de la vida del individuo, ha generado una fiesta nueva con mensajes nuevos, pero en la que la que la poesía popular sigue siendo central.

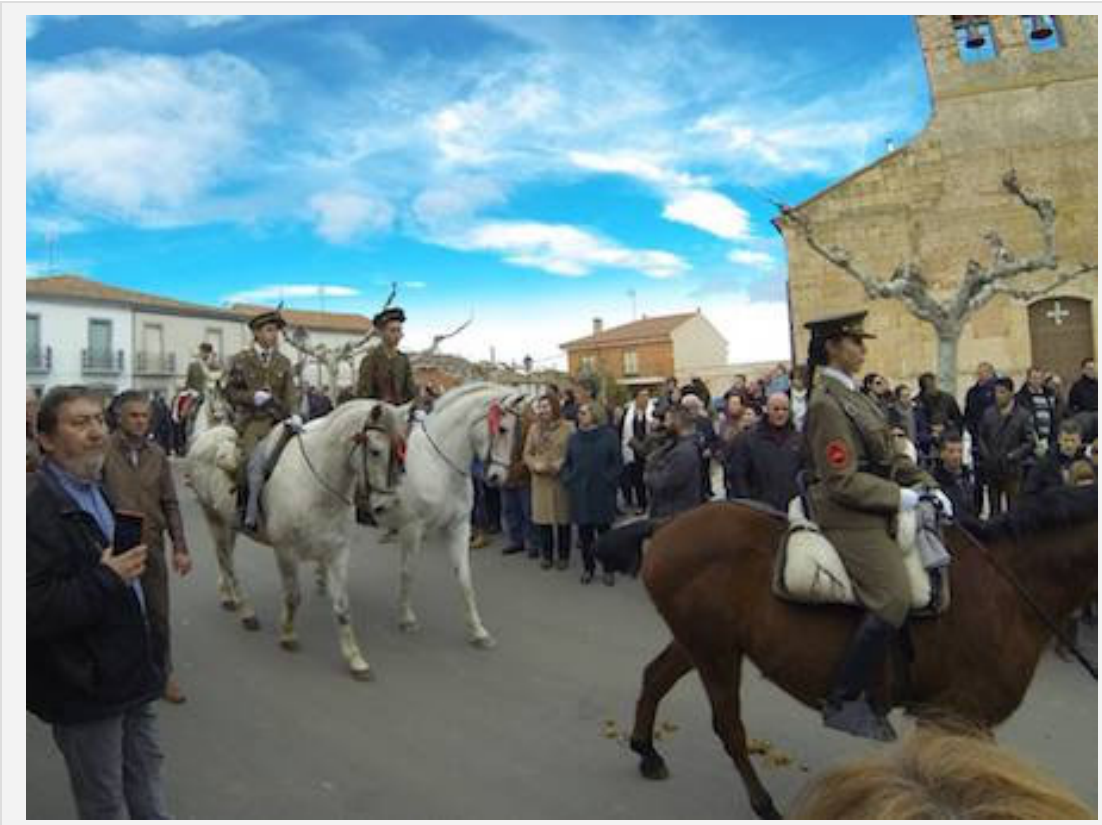

Los quintos preparados para recitar sus relaciones y correr sus gallos (Guarrate, 2016). Fotografía: Antonio G. Rosón. 


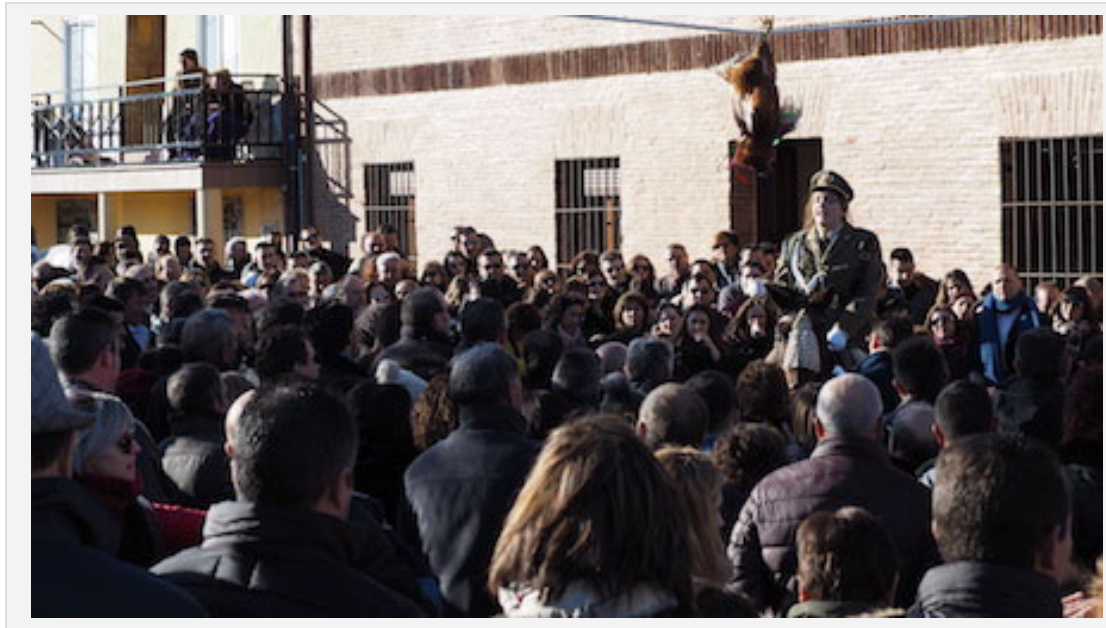

Una quinta dice su relación ante su gallo (Guarrate, 2018). Fotografía: Antonio G. Rosón.

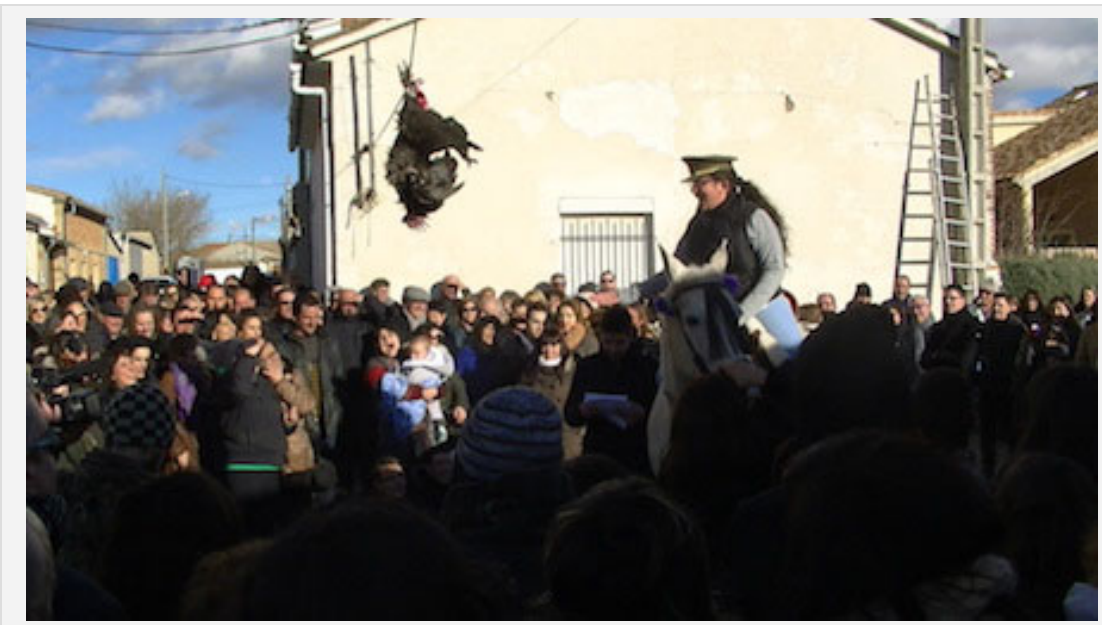

El humor, la ironía, el chiste, la mímica y al recitar unas "noticias" sabidas que se presentan como nuevas provocan una catarsis colectiva (EI Pego, 2015). Fotografía: Antonio G. Rosón.

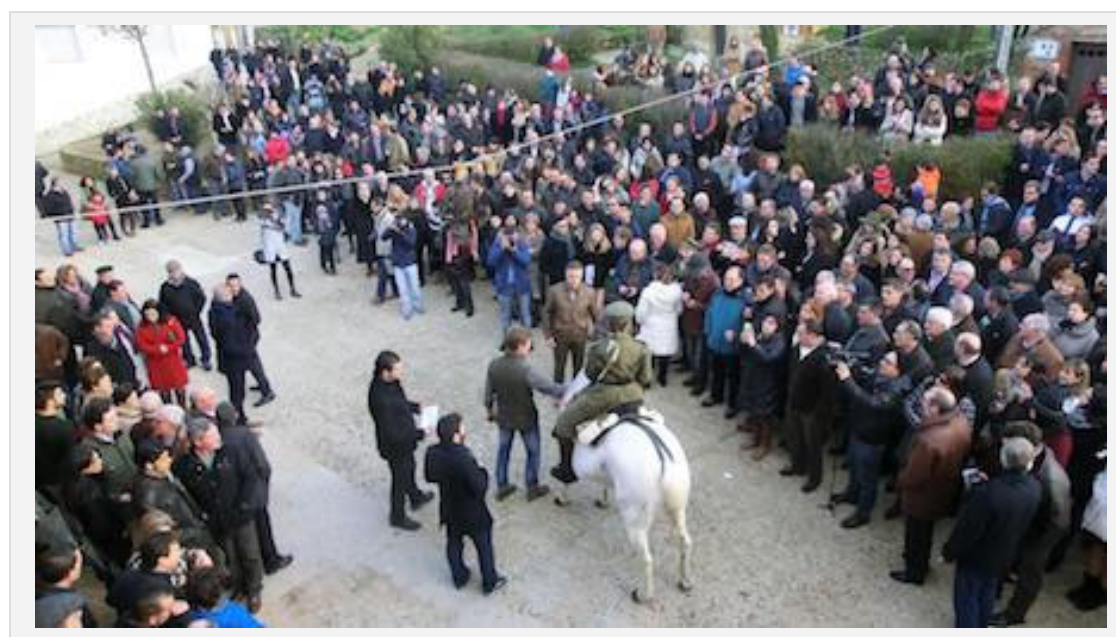

Una quinta va a recibir la espada para correr el gallo tras su relación (Guarrate, 2016). Fotografía: Antonio G. Rosón. 


\section{Conclusiones}

Podemos observar que muchas de las antiguas versificaciones rurales en Castilla y León han muerto simplemente porque los rituales en los que nacieron han desaparecido. Sin embargo, en muchos casos se han fijado con la escritura a través de cancioneros o colecciones de diversos poemas como los brindis. Los que han desaparecido lo han hecho por diversas causas como la atonía demográfica, el conflicto generacional o la desafección hacía tradiciones que se tienen por obsoletas, aunque siempre exista la posibilidad de recuperarlas en clave identitaria si cambia la valoración de las mismas.

En los casos en los que una tradición versificadora pervive a pesar de los embates de la modernidad la podemos calibrar en la intersección de la perspectiva diacrónica y la sincrónica. Desde un punto de vista emic los mantenedores de la tradición sostienen que es la misma de siempre, aunque reconocen algunas modificaciones. Sin embargo, si la valoramos desde un punto de vista etic aplicando una mirada etnohistórica veremos que la configuración social y cultural de las comunidades opera cambios de calado en la tradición. Estos afectan a los versos que se componen ex profeso para determinados ritos, los de paso, protagonizados por los quintos son un buen ejemplo, en función de los cambios socio-culturales.

En estas composiciones poéticas los versificadores reciclan otras composiciones dadas por la tradición y, con formas métricas sancionadas (décimas, quintillas, cuartetas, coplas o romances), ofrecen lo que es "noticia" y materia de interés para el auditorio clásico, el que participa en el rito como comunidad. Al mismo tiempo los ritos se abren a otros, los espectadores ocasionales y ajenos a la propia comunidad. Es posible que para los últimos algunos ritos se perciban como rarezas étnicas, aun cuando estuvieron muy generalizados, pero todavía en el siglo XXI hay vates locales y recitadores de poemas normalizados en contextos determinados. Su pervivencia en el tiempo festivo del carnaval refrenda la memoria colectiva del pueblo en clave lúdica en la que lo rural no se destruye ni se desintegra, sino que se articula como una nueva ruralidad en el espacio global (Roseman y otros 2013: 5). El hecho de recitar es un acto creativo en el que el recitador crea e improvisa al tiempo que repite una comunicación.

\section{Notas}

1. Agradecemos al profesor Alonso Ponga que comparta esta información inédita y la que sigue, así como la autorización para publicarla.

2. Los brindis ejecutados por brindeiros fueron una de las atracciones de las bodas gallegas dese el siglo XIX y hasta bien entrado el XX en los que demostraban sus aptitudes para improvisar (Díaz Pimienta 2003: 292).

3. Tradicionalmente han existido las carreras de cintas y las carreras de gallos, pudiendo darse las dos en un mismo lugar. Sin embargo, en estas últimas, aunque en ocasiones se utilizaban cintas o argollas, "juego de cintas", a modo de piñata para el ritual, lo habitual era decapitar gallos, pudiendo ser otra ave, que o bien pendían de una cuerda o bien estaban enterrados sobresaliendo solo su cabeza. En cualquier caso, el sacrificio lo llevaban a cabo varones o mujeres jóvenes con una espada, una pica o con la mano. Sobre las diferentes tipologías puede verse Luis Díaz de Viana (1982: 188-189). Una de las que menciona es la decapitación del gallo por mujeres que celebran santa Águeda. Recogimos en Fombellida (Valladolid), en una entrevista e 8 de febrero de 2004, la costumbre ya perdida del sacrificio de dos gallos adornados por cintas, aunque estos no se decapitaban, sino que eran perseguidos por las mujeres el 5 de febrero en una era y después se sacrificaban para consumirlos en una cena por las mismas mujeres.

4. Recogimos versos en Autilla del Pino (Palencia) en una entrevista en octubre de 2001. Echar los refranes y la carrera de gallos y cintas por san Antón era ya un rito perdido. También tuvimos noticias en Grijota, Villamartín y Torremormojón (Palencia). En este último lugar se recuperó el rito incruento en el año 1998 de forma esporádica. En Meneses de Campos (Palencia) desapareció en el año 1955. Recogimos noticias de la misma celebración en otras fechas como carnaval (Cabreros del Monte, en Valladolid, y Villoldo, en Palencia) o en la fiesta patronal de la Santa Cruz en Villabrágima (Valladolid) donde se mantiene la carrera de cintas a caballo. 
5. Tiradas que recogimos en Renedo de Esgueva en dos entrevistas el 13 de enero y el 5 de marzo de 2004 con informantes de edades muy avanzadas.

6. La realizamos en octubre de 2001. Véase, además, la recopilación de cuartetas, con edición y estudio, de María Victoria Weber-Antón (2017) en la que describe las dos fiestas, quintos y san Antón, con el mismo grupo de edad como protagonistas de ambas. Se puede ver la celebración actual en https://sancebriandecampos.es/index.php/turismo/fiestas/san-anton-y-quintos/

7. Se mantienen las relaciones o coplas y las carreras de gallos en otros pueblos de la comarca de la Tierra del Vino, a veces de forma simbólica cuando no hay quintos como se refleja en la prensa provincial. En la misma comarca se celebra en el ciclo de carnaval en Fuentespreadas en San Esteban, en Villamor de los Escuderos en san Antón, en El Pego el día de Las Candelas y en San Miguel de la Ribera en carnaval. En el alfoz de Toro se perpetúa la carrera en carnaval en San Miguel de la Ribera.

8. Las quintas tradicionalmente participaban como los quintos en todos los actos, excepto en la relación y carrera de gallos. Desde finales de la década de 1990 participan en igualdad.

9. Le agradecemos el envío de algunas de las relaciones compuestas por él en los últimos años y algunas informaciones relativas a la composición de las mismas. Relacioneros de varias familias se encargaron de componerlas hasta la década de 1980 (de Dios y Riesco especialmente; véase MartínezDurbán 1980) que han continuado él mismo cometido en los últimos años. Los vates de los últimos tiempos son el propio Luis Miguel de Dios, Teodosio Rosón Galache, Jesús Riesco Rodríguez y Antonio de Dios siguiendo la tradición familiar en el oficio de componer relaciones.

10. Antonio G. Rosón, cámara de televisión, alquiló un equipo para grabar y otro para editar con sus medios particulares. Nos ha dicho que le resultó imposible conseguir financiación pues, simplemente, no se podía ni plantear grabar la carrera de gallos en un momento en que se promulgan las primeras leyes en España sobre la protección de los animales, la pionera es la catalana de 1988. Según su autor, al que agradecemos el acceso al documental, "era impensable a pesar de que el gallo no era lo más importante". En el momento histórico que se grabó la amenaza de prohibición era muy real y, de hecho, seis años más tarde los gallos en Guarrate ya se cuelgan muertos (Pellicer 1997). El debate estaba en la prensa provincial que el 23 de agosto de 1993 publicó un artículo de opinión firmado por el antropólogo Francisco Rodríguez Pascual (2012: 133-134) titulado "Zamora se divierte con el dolor de los animales" a favor de las fiestas tradicionales sin sangre.

\section{Bibliografía}

Alonso Ponga, José Luis

1979 “La picaresca de los Oteros (León)”, Tierras de León, n 36-37: 165-175.

1986 Religiosidad Popular Navideña en Castilla y León: Manifestaciones de carácter dramático. Salamanca, Junta de Castilla y León. Consejería de Educación y Cultura.

2012 "La fiesta del gallo en Guarrate: rituales lúdicos y juegos ritualizados", Voci. Annuale di Scienze Umane, anno IX: 9-26.http://voci.info/biblioteca_12/PONGA.pdf

Benito Riesco, Orlando

2006 “A propósito de un ritual. 'Correr el gallo', un rito de iniciación”, Gazeta de Antropología, n 22, artículo 17. http://hdl.handle.net/10481/7103

Caro Baroja, Julio

1965 El carnaval (análisis histórico-cultural). Madrid, Alianza Editorial, 2006.

Castellanos, Basilio Sebastián de

1847 "De la fiesta y prácticas del carnaval; y del burlesco Entierro de la Sardina", Museo de las Familias (Madrid), 25 de febrero: 36-41.

1848 "De la romería titulada de las vueltas de san Antón", Museo de las Familias (Madrid), 25 de enero: $19-21$. 
Cervantes, Miguel de

1605 Don Quijote de la Mancha, vol. I. Madrid, Cátedra, 1996.

Díaz, Joaquín

1983 "Editorial", Revista de Folklore (Urueña, Valladolid), nº 34.

Díaz Viana, Luis

1982 "El juego de Gallos. (Formas, textos e interpretación)", Revista de folklore, t. 2b, n 24: 183-191.

http://www.cervantesvirtual.com/nd/ark:/59851/bmc4t8c2

Díaz Pimienta, Alexis

2003 "La poesía oral improvisada: un ritual desconocido", en Ritualidades latinoamericanas: un acercamiento interdisciplinario / Uma aproximaçã o interdisciplinar. Madrid, Editorial Iberoamericana/Vervuert: 281-304.

https://elibro-net.ponton.uva.es/es/ereader/uva/36790?page=7.

2008 "La décima como estrofa para la improvisación", en La voz y la improvisación. Imaginación y recursos en la tradición Hispánica. Urueña, Fundación Joaquín Díaz: 106-127.

2013 Teoría de la Improvisación Poética. Almería, Scripta Manent Ediciones.

[Domínguez] Berrueta, Mariano

1941 Del cancionero leonés. León. https://bibliotecadigital.jcyl.es/es/consulta/registro.do?id=898

Domingues Polanah, Luis Antonio

1996 Campesinos de Sayago. Estructura social y representaciones simbólicas de una comunidad rural. Zamora, Caja España.

Goody, Jack

1977 La domesticación del pensamiento salvaje. Madrid, Akal, 2008.

Isla, José Francisco de

1995 Historia del famoso predicador Fray Gerundio de Campazas, alias Zotes. Madrid, Cátedra. Ed. de Enrique Rodríguez Cepeda.

Manzano, Miguel

1982 Cancionero de folklore musical zamorano. Madrid, Alpuerto.

1988-1991 Cancionero leonés, 6 vols. León, Diputación Provincial.

2001 Cancionero popular de Burgos, 7 vols. Burgos, Diputación Provincia de Burgos.

2011 Cancionero básico de Castilla y León: selección, ordenación y estudio. Valladolid, Junta de Castilla y León-Consejería de Cultura y Turismo.

Olmeda, Federico

1903 Folk-lore de Castilla o Cancionero popular de Burgos. Sevilla, Librería Editorial de María Auxilidora. https://bibliotecadigital.jcyl.es/es/consulta/registro.do?id=2904

Ong, Walter J.

1982 Oralidad y escritura. Tecnologías de la palabra. Buenos Aires, Fondo de Cultura Económica, 2006.

Panero García, María Pilar

2020 “'Que de hoy en un año'. La oralidad en una mascarada: Los Carochos de Riofrío de Aliste”, Boletín de Literatura Oral, vol. extraordinario, $n^{\circ}$ 3: 29-59. DOI: 10.17561/blo.vextra3.5252

Puerto, José Luis

2010 "Santuarios y ermitas: una topografía de lo sagrado", en La religiosidad popular en tierras de león. León, Fundación Hullera Vasco-Leonesa: 9-52.

Rodríguez, Marie-Soledad

2006 "Les corridas de gallos en Castille-Léon: entre rite et fête, un loisir identitaire", en Fr. Étienvre y S. Salaün (éd.), Du loisir aux loisirs (Espagne XVIIIe-XXe), Université Paris 3: 79-93.

https://crec-paris3.fr/wp-content/uploads/2011/07/05-rodriguez1.pdf

Rodríguez González, Pedro

2002 "Los quintos de Valdecarros", Revista de Folklore, t. 22b, n 260: 39-46. 
http://www.cervantesvirtual.com/nd/ark:/59851/bmc2z313

Rodríguez Pascual, Francisco

2012 Las animales en la cultura tradicional zamorana. Etnozoología. Zamora, Semuret.

Roseman, Sharon R. (y otros)

2013 "Antropología y nuevas ruralidades", Gazeta de Antropología, n 29 (2), artículo 01.

http://hdl.handle.net/10481/28509

Sánchez Gómez, Luis Ángel

1991 Sayago. Ganadería y comunalismo agropastoril. Zamora, Caja España.

Sanz, Ignacio

1997 El vino en la cultura popular: brindis del vino. Valladolid, Ediciones Castilla.

Temprano Peñín, María Soledad

1995 "El gallo: el otro protagonista de las 'Fiestas de quintos'", Revista de Folklore, t. 15a, $\mathrm{n}^{\circ} 173$ : 169-173.http://www.cervantesvirtual.com/nd/ark:/59851/bmcnw187

Trapero, Maximiano

2020 Un arte verbal muy vivo y vivaz. Estudios sobre la décima y la improvisación poética. Madrid, CIOFF España.

Tucídides

Historia de la Guerra del Peloponeso. México D. F., Porrúa, 2010.

Valderas, Alejandro

2009 El ramo de Navidad. León, Edilesa.

Weber-Antón, María Victoria

2017 Un siglo de poesía pinchorrera. Cuartetas de quintos. Palencia, Institución Tello Téllez de Meneses.

\section{Filmografía}

Martínez-Durbán, Rafael (dir.)

1980 "Correr los gallos en Guarrate", en Informe Semanal. RTVE [reportaje].

https://www.youtube.com/watch?v=T7j.jpzCryL0

Pellicer, Ramón (dir.)

1997 "Correr el gallo", en Testigo directo. RTVE [reportaje].

Rosón, Antonio G.

1991 A correr el gallo. Autoproducido [documental]. 